\title{
HYPOXIA/HYPERCAPNIA PREVENTS IRON-DEPENDENT COLD INJURIES IN CORD BLOOD STEM AND PROGENITOR CELLS
}

Sandie Gerby ${ }^{1}$, Mathias Simplicien ${ }^{1}$, Pascale Duchez ${ }^{1,2}$, Jean Chevaleyre ${ }^{1,2}$, Zoran Ivanovic ${ }^{1,2}$, Marija Vlaski-Lafarge ${ }^{1,2}$

1) Etablissement Français du Sang Nouvelle-Aquitaine, Bordeaux, France

2) INSERM U1035 University of Bordeaux, France

*Corresponding author:

Dr Marija Vlaski Lafarge, PhD

Nouvelle-Aquitaine-Branch of French Blood Institute (Etablissement Français du Sang NouvelleAquitaine), Place Amélie Raba Léon, CS 210103075 Bordeaux Cedex, France

e-mail : marija.vlaski@efs.sante.fr

phone : +33556907550

fax : +335569075 51

Running title: Stem cell maintenance in hypothermia 


\begin{abstract}
Background: Cold-induced cell injuries are associated with an increase in the cellular labile iron pool followed by lipid peroxidation and alteration of mitochondrial function which lead to cell death. Recently, we showed that incubation in a hypoxic/hypercapnic $(\mathrm{HH})$ gas mixture improved the survival of a population of cord blood hematopoietic progenitors and stem cells $\mathrm{CD}_{3} 4^{+}$in severe hypothermia. In order to explain the underlying mechanism, here we test if this $\mathrm{HH}$-induced cytoprotection in cold conditions is associated with the level of labile iron pool (LIP) and lysosome stability.
\end{abstract}

Methods: Cord blood CD34 ${ }^{+}$cells were incubated in air $\left(20 \% \mathrm{O}_{2} / 0.05 \% \mathrm{CO}_{2}\right)$ or in the hypoxic $(5 \%$ $\left.\mathrm{O}_{2}\right) /$ hypercapnic $\left(9 \% \mathrm{CO}_{2}\right)$ atmosphere for 7 days at $4^{\circ} \mathrm{C}$ and analysed.

Results: Incubation in $\mathrm{HH}$ condition maintained the day 0 (D-O) level of LIP detected using a bleomycin-dependent method. This was associated with preservation of lysosome integrity and a higher cell survival. Conversely, in the air condition LIP was significantly increased. Also, the presence of a moderate concentration of iron chelator deferoximine improves the conservation of total $\mathrm{CD} 34^{+}$ cells and committed progenitors in air condition. Pre-treatment of $\mathrm{CD} 34^{+}$cells with the lysomotropic agent imidazole induces significant decrease in the lysosomal stability and in all conditions. This is associated with the important decrease of survival of conserved cells and increase in the cellular LIP level.

Discussion: Our study showed that $\mathrm{HH}$ gas mixture cytoprotection during hypothermia maintains lysosome stability, which enables preservation of the cellular chelatable iron in the physiological ranges. These findings suggest a way to optimize cell conservation without freezing.

Keywords: CD34 ${ }^{+}$cells; conservation; hypoxia; hypercapnia; hypothermia, iron; lysosomes. 
Abbreviations: labile iron pool (LIP); reactive oxygen species (ROS); hematopoietic stem and progenitors cells (HSC/HPC); hypoxic/hypercapnic gas mixture, $(\mathrm{HH})$; propidium iodide (PI); Colony Forming Cell (CFC); deferoxamine (DFX); ethylenediaminetetraacetic (EDTA); bicinchronic acid (BCA); acridine orange (AO); 7-amino-actinomycin (7-AAD); Colony Forming Unit-Spleen (CFU-S). 


\section{Introduction}

Storage in severe hypothermia $\left(4^{\circ} \mathrm{C}\right)$, for more than few days, triggers cellular injuries. It is generally proposed that the primary cause of damage comes from the cold-induced mismatch between ATP supply and demand, leading to a cellular energy deficit. Consequently, the failure of ion-motive ATPases is followed by an impairment of ionic balance. This leads to membrane depolarization and an uncontrolled influx of $\mathrm{Ca}^{2+}$ through voltage-gated $\mathrm{Ca}^{2+}$ channels, resulting in the activation of $\mathrm{Ca}^{2+}-$ dependent hydrolases, and in turn provoking further membrane depolarization, uncontrolled cell swelling and ultimately, cell necrosis $[1,2]$. These events are potentiated by the behaviour of plasma membrane lipids in hypothermia which undergo lipid phase transition interfering with membrane function, leading to ions leakage [3].

More recent studies have shown in various cell types that cold-induced cell injuries are associated with an increase in the cellular chelatable labile iron pool (LIP), initiating the formation of reactive oxygen species (ROS) [4-7]. The increase in ROS levels is usually followed by a massive lipid peroxidation, alteration of mitochondrial function and loss of lysosome integrity, which can lead to cell necrosis in hypothermia or apoptosis upon rewarming [4].

Hematopoietic stem and progenitors cells (HSC/HPC) are very sensitive to hypothermia, and their optimal storage conditions (conservation medium, temperature, duration) are critical for the successful stem cell transplantation [8].

Surprisingly, the mechanisms of the cold-induced injuries of HSC/HPC have been poorly explored. Recently, we described a method for prolonged cold storage enabling functional preservation of cord blood (CB) HSC/HPC in the hypoxic/hypercapnic $(\mathrm{HH})$ gas mixture $[9,10]$. In order to explain the underlying mechanism, here we test if this $\mathrm{HH}$-induced cytoprotection in cold is associated with the level of LIP and lysosome stability. 


\section{Material and methods}

$\mathrm{CD} 34^{+}$cell processing

Purification. CB samples delivered (with the mother's approval) to the Cell Therapy Unit of the French Blood Institute, Bordeaux, rejected for banking, were used in experiments. CD34 ${ }^{+}$cells from umbilical CB were isolated using an immunomagnetic technique (Miltenyi Biotec, Paris, France).

Conservation. $\mathrm{CD}^{+} 4^{+}$cells $\left(5 \times 10^{4} / \mathrm{ml}\right)$ were plated in Stem $\alpha$ S3 (Stem Alpha SA, Saint Genis, I'Argentière, France), incubated in $\operatorname{air}\left(20 \% \mathrm{O}_{2} / 0.05 \% \mathrm{CO}_{2}\right)$ or in the hypoxic $\left(5 \% \mathrm{O}_{2}\right)$ /hypercapnic atmosphere $\left(9 \% \mathrm{CO}_{2}\right)$ for 7 days at $4^{\circ} \mathrm{C}$. All the tests were performed with purified (D-0) and stored CD $34^{+}$cells after 7 days at $4^{\circ} \mathrm{C}(\mathrm{D}-7)$. In order to obtain the desired gas mixtures, the open flasks with cell suspension were incubated in a $\mathrm{O}_{2}$ and $\mathrm{CO}_{2}$ culture chamber equipped with $\mathrm{O}_{2}$ and $\mathrm{CO}_{2}$ controllers (PRO-OX and PRO- $\mathrm{CO}_{2}$, Biospherix, Lacona, NY) for $1 \mathrm{~h}$ at room temperature then plugged and transferred to $4 \mathrm{C}^{\circ}$ conditions for 7 days. In some variants of the experiment, deferoxamine (DFX) (Sigma Aldrich) was added to the conservation medium. For the estimation of the effect of the lysosomotropic agent on the cell conservation, cells were pre-incubated for $1 \mathrm{~h}$ at $37^{\circ} \mathrm{C}$ with $250 \mathrm{mM}$ imidazole (Sigma Aldrich) in Dulbecco's Modified Eagle's medium (Thermo Ficher Scientific) supplemented with $2 \%$ foetal calf serum (HyClone Perbio, Bezons, France) and 10 mM HEPES buffer (Sigma Aldrich), washed and resuspended in conservation medium before transfer to $4^{\circ} \mathrm{C}$. Cells were harvested at D-7 and then analysed.

Apoptosis assay

Apoptosis was determined with Annexin V-FITC kit (Beckman Coulter, Roissy, France) following the manufacturer's protocol. Briefly, $10^{5} \mathrm{CD}^{4} 4^{+}$cells were labelled with Annexin V-FITC solution (AnnV) 
and propidium iodide (PI) $(10 \mathrm{mg} / \mathrm{ml})$ for $15 \mathrm{~min}$ at $4^{\circ} \mathrm{C}$, then washed in phosphor buffer saline and analysed with a flow cytometer (Beckton Dickinson FACSCanto II).

Hematopoietic committed progenitor cell determination-Colony Forming Cell (CFC) assay

The committed progenitors CFCs (colony-forming unit-granulocyte, monocyte [CFU-GM] plus burstforming unit-erythroid [BFU-E]) were assayed as previously described [9]. Briefly, D-0 and D-7 CD34 ${ }^{+}$ cells $(250$ cells $/ \mathrm{ml}$ and 600 cells $/ \mathrm{ml}$, respectively) were seeded in methylcellulose Stem Alpha-1D (Stem Alpha, Stem Alpha Saint Genis l'Argentière, France) supplemented with Recombinant human stem cell factor (SCF), Recombinant human interleukin 3 (IL-3), Recombinant human erythropoietin (EPO) and recombinant human granulocyte-macrophage colony-stimulating factor (GM-CSF). After 14 days incubation, CFCs were counted.

Ferritin content measurement

The assay was performed using $10^{5} \mathrm{CD} 34^{+}$cells harvested at D-0, or D-7 conservation in air or $\mathrm{HH}$ conditions. Total proteins were extracted with RIPA buffer ( $50 \mathrm{mM}$ Tris $/ \mathrm{HCl} \mathrm{pH} \mathrm{7.5,} 150 \mathrm{mM} \mathrm{NaCl}, 1$ $\%$ Triton $X 100,0.5$ Na-deoxycholate, $0.1 \mathrm{mM}$ cocktail of protease inhibitors, $1 \mathrm{mM}$ ethylenediaminetetraacetic (EDTA); the reagents were purchased from Sigma Aldrich) and quantified with a bicinchronic acid (BCA) (Thermo Ficher Scientific) based method. Ferritin content was determined in protein extracts according to the manufacturer's instructions (Human Ferritin ELISA Kit, Sigma Aldrich). Quantity of ferritin was determined with biotinylated detection antibodies in the presence of horse radish peroxidase conjugated streptavidin. Trimethylbenzidine substrate was added and the intensity of absorbance of the coloured product was measured at $450 \mathrm{~nm}$ (Evolis, Biorad). 
Lysosome integrity analysis

Lysosome stability was determined by acridine orange (AO, Molecular Probes) staining, as showed previously [11]. Briefly, $10^{5} \mathrm{CD} 34^{+}$cells were treated with $\mathrm{AO}(25 \mathrm{nM})$ at $37^{\circ} \mathrm{C}$ for 30 min. To exclude dead cells, 7-amino-actinomycin (7-AAD) was added (BD Bioscience). After rinsing, the step pellet was resuspended in phosphate buffer saline (Lonza, Verviers, Belgium) and analysed with a flow cytometer. Excitation was obtained with argon laser $(488 \mathrm{~nm})$ and the acquisition was effected in the phycoerythrin emission spectra using filter $585 / 40 \mathrm{~nm}$.

Bleomycin-based labile iron determination

LIP was measured using bleomycin-detectable iron assay [12]. All the solutions used in the assay were Chelex 100 (Sigma Aldrich) treated in order to eliminate residual iron. All the reagents were purchased from Sigma Aldrich, it being stated in the article otherwise. $\mathrm{CD} 34^{+}$cells, harvested at D-0 and D-7 of conservation, were washed with Hank's Balanced Salt Solution (Thermo Fisher Scientific) and then lysed (TRIS/HCl at $20 \mathrm{mM}(\mathrm{pH7.4})$ with TRITON X-100 $1 \%$. Cell lysates were mixed with 0.25 $\mathrm{ml}$ of calf thymus DNA (1 mg/ml), $0.05 \mathrm{ml}$ of $5 \mathrm{mM} \mathrm{MgCl}_{2}, 0.025 \mathrm{ml}$ of bleomycin sulphate $(1 \mathrm{mg} / \mathrm{ml})$ (Calbiochem), and ascorbic acid ( $8 \mathrm{mM})$. After incubation at $37^{\circ} \mathrm{C}$ for $30 \mathrm{~min}$ in a shaking water bath, malondialdehyde is produced proportionally to the quantity of $\mathrm{Fe}^{2+}$ ions. The reaction was stopped with $0.5 \mathrm{ml}$ of $0.1 \mathrm{M}$ EDTA. The contents were then mixed with $0.5 \mathrm{ml}$ of $1 \%$ thiobarbituric acid (in 50 $\mathrm{mM} \mathrm{NaOH}$ ) and $0.5 \mathrm{ml} 25 \% \mathrm{HCl}, \mathrm{v} / \mathrm{v}$ and incubated at $95^{\circ} \mathrm{C}$ in order to transform the malondialdehyde into a coloured product. Intensity of absorbance was read at $532 \mathrm{~nm}$ (Specord, Analytik Jena). Values were calculated using the $0.10 \mathrm{ml}$ of a $0.25-20 \mu \mathrm{M} \mathrm{FeCl}_{3}$ as a standard. 


\section{Statistical analysis}

The Wilcoxon-Mann-Whitney comparison test was used to examine the statistical significance of the differences between the various experimental conditions $(p<0.05$ was considered statistically significant).

\section{Results}

\section{Conservation in HH maintains LIP at the steady-state level}

The labile iron pool (LIP) is thought to be involved in causing cell death during hypothermia [5]. In order to examine if $\mathrm{HH}$ induces the same phenomenon, we measured bleomycin-dependent LIP in our conditions [13]. Our results showed that a 7-day exposure to HH maintained the day 0 (D-0) level of LIP detected using bleomycin-dependent method. This D-0 content of LIP cells we refer to as the physiological (steady-state) LIP level. Conversely, in the atmospheric air usually used for cell storage at $4^{\circ} \mathrm{C}$, cellular LIP was significantly increased compared to $\mathrm{D}-0$ level (Figure $1 \mathrm{~A}$ ).

The presence of an iron chelator in the conservation medium DFX improved the maintenance of CD34 ${ }^{+}$cells in a dose-dependent manner in air condition, indicating that iron dependant injuries underline cell degradation in the cold. However, when in the HH condition - where LIP is maintained in the physiological range - the presence of DFX did not significantly increase total cell maintenance (Figure 1B)

In addition, committed progenitors (CFCs) are significantly better preserved in the presence of a moderate concentration of DFX in air condition. But, stronger iron chelation by a high concentration of DFX abrogates the maintenance of CFCs, especially erythroid progenitors BFU-E, and this in all experimental conditions. This implies that iron is indispensable for CFCs survival. In addition, our results suggest that the increase of LIP above this physiological range, as well as its drop below 
steady-state level induced by DFX-chelation, abrogates the survival of hematopoietic progenitors (Figure 1C).

\section{Conservation in HH maintains lysosome integrity and ferritin content}

Hypothermic cell injuries might be attenuated by the chelation of LIP with a high iron storage protein ferritin-dependant mechanism [13]. In order to determine if the $\mathrm{HH}$ condition displays its cytoprotective effect via the ferritin dependant mechanism, we examined cellular ferritin content. Our results showed that at D-7 there is no statistical difference between experimental conditions, with results similar to the ferritin level detected in the D-0 CD34 $4^{+}$cells (Figure $2 A$ ).

Lysosomes contain redox active iron that could leak into the cytoplasm when the lysosomal integrity is altered. The release of this iron and hydrolytic enzymes may contribute to subsequent cell death and cold-induced cell injuries [14]. In view of this, lysosome integrity upon incubation in hypothermia was analysed by acridine orange ( $\mathrm{AO})$, fluorescent dye taken up by proton trapping and retained inside acidic organelles such as lysosomes [11]. After 7 days of incubation in hypothermia and air condition mean fluorescence intensity (MFI) of $A O$ is significantly diminished compared to the D-0 level, indicating important lysosome degradation. By contrast, in $\mathrm{HH}$ condition, MFI is similar to D-0 level of $\mathrm{CD}_{3} 4^{+}$cells, indicating that lysosomes are protected from degradation when hypothermic incubation takes place in the $\mathrm{HH}$ mixture (Figure 2B).

Preservation of lysosome integrity using $\mathrm{HH}$ mixture during hypothermia correlates with cell survival and stabilisation of LIP level

In the order to discern the relationship between the $\mathrm{HH}$-mediated maintenance of lysosome integrity and cell survival during hypothermic storage, we pre-treated $\mathrm{CD} 34^{+}$cells with a lysomotropic agent 
imidazole. Our results showed that imidazole induces a significant decrease in lysosomal stability after 7 days of incubation, and this in a similar manner in air- and $\mathrm{HH}$ conditions compared to D-O (Figure 3A). This alteration of lysosome integrity correlates with the significant increase in LIP level compared to D-0 in both conditions (Figure 3B). Also, it coincides with a high decrease in survival of conserved $\mathrm{CD} 34^{+}$cells in either gas mixture (Figure $3 \mathrm{C}$ ).

\section{Discussion}

Our study indicates that cytoprotection in $\mathrm{HH}$ against severe hypothermia is mediated by the stabilisation of lysosome integrity, and that iron-dependant cold-induced injuries are critical for the survival of $\mathrm{CB} C D 34^{+}$cells. We show here that this issue is valid for total $\mathrm{CD} 34^{+}$cell population (consisting mainly of various hematopoetic progenitors and rare stem cells [15]) as well as its CFC fraction.

Lysosomes contain redox-active iron and a wide spectrum of hydrolytic enzymes, which could provoke death when released into the cytoplasm [16]. Also, lysosomes have been identified as being particularly susceptible to hypothermia; a decline in lysosome integrity is consistent with coldinduced loss in cell viability [14]. These observations have been proved for the various cells types and organs $[14,17-19]$ and here we reported similar data for the hematopoietic progenitors.

In our study, when lysosomal stability is compromised, the cytoprotective effect of HH during hypothermia is significantly abrogated, which correlates with an increase in LIP and a decrease in cell viability (Figure 3 ).

Our results fit with previously published data showing that one of the consequences of alteration of lysosome integrity on cell survival during hypothermia, is the release of chelatable iron $[5,14,20]$. In presence of the ROS, which were shown to have increased in hypothermic conditions (other authors' and our data $[5,9])$, the oxidative iron-dependant Fenton-type reactions can take place [5]. It was 
reported that this might result in massive lipid peroxidation which, in turn, attacks the lysosomes but also other cell membrane structures, and leads to cold-induced injuries [16].

Interestingly, our work suggests that LIP, but not oxidative stress, is particularly important in the occurrence of cold-induced injuries and cell death in hematopoietic progenitors. More specifically, we showed recently that $\mathrm{HH}$ cytoprotection is ruled out despite a sustained ROS production [9]. Also, in this study, the maintenance of LIP within the physiological range is crucial for the survival of hematopoetic progenitors, since its increment above steady-state level abrogates $\mathrm{HH}$-mediated cell protection in hypothermia (Figure 3).

Thus, we propose that functional preservation of $\mathrm{CD} 4^{+}$cells in hypothermia by $\mathrm{HH}$ involves stabilisation of the lysosome membrane, which prevents release of LIP that could provoke deadly cold-induced injuries in the presence of hypothermia-produced ROS. This raises the question of how the $\mathrm{HH}$ gas mixture stabilises the lysosome membrane in the first place? A possible explanation lies in the fact that hypercapnic condition creates a slightly acidic environment (intra and extra cellular) when in hypothermia, we have shown this previously [9]. In hypercapnic condition $\mathrm{CO}_{2}$ diffuses across the membrane, enabling a permanent load of carbonic acid and protons in the cytosol. In these conditions, the plasma membrane lipid bilayer is protected from cold-induced injuries $[7,9]$. In addition to the plasma membrane, this protecting effect could be applied to all other cellular membrane structures including the lysosome.

Thus, according to our previous work and these findings, we suggest that preservation of $\mathrm{CD} 34^{+}$cells during hypothermic storage is mediated by the double action of $\mathrm{HH}$ gas mixture: hypercapnia diminishes the occurrence of cold-induced injuries, while hypoxia prevents apoptosis upon rewarming after the transfer to $37^{\circ} \mathrm{C}[9,10,21]$.

Since LIP has a critical role in cell survival during hypothermic incubation of cultured cells, improved cell preservation was accomplished by the utilisation of conservation medium supplemented with 
iron chelators $[5,7]$. In this study, DFX added in the conservation medium improved cell viability only in the conditions where LIP was above steady-state (D-0) level in CD34+ cells (Figure 1).

At $37^{\circ} \mathrm{C}$, DFX is internalised by endocytosis and localised exclusively in lysosomes, where it act as a chelator of intralysosomal iron, stabilising the lysosomes [22]. At $4^{\circ} \mathrm{C}$ endocytosis is blocked, the DFX remains in the extracellular compartment, where it removes the iron from the extracellular space. But, since extracellular labile iron could pass through the membrane, the presence of DFX in the extracellular compartment [23] could diminish intracellular iron too.

With our method, the DFX is added to the conservation medium during the preparation phase dedicated to obtaining the desired gas mixture, which is done at room temperature. At this temperature, DFX could slowly enter the intracellular compartment by endocytosis but could not be trafficked to the lysosomes[24]. Thus, with this method, the DFX could capture the iron from the intra as well as the extracellular environment.

On the other hand, our results showed that a decrease below steady-state level of LIP with the highest dose of DFX is not compatible with the survival of commited hematopoetic progenitors in either gas mixtures (Figure 1C). These results were expected since it has been shown in the model of anemic Belgrade laboratory $(\mathrm{b} / \mathrm{b})$ rat [25], that severe deficiency of intracellular iron provoked by the mutation of the iron transport protein Nramp2 [26] blocks the proliferation of the hematopoietic progenitors (in this case Colony Forming Unit-Spleen, CFU-S) [27]. This was completely overpassed by the treatment of $b / b$ rats with a high dose of molecular iron or a non-toxic dose of hemin [25].

With our method, incubation in HH preserves functional CB stem and progenitor cells significantly more efficiently than other models of cold storage without freezing $[9,10]$. Here we revealed that lysosome stability and iron-dependant cold-induced injuries are the critical issue for hematopoietic progenitor cold preservation. In this regard, we think that the addition of iron chelators or stabilisers of the lysosome membrane are the way to optimise CB storage survival. Our approach could be an alternative to freezing in clinical practice in some situations. This should enable avoiding 
cryopreservation of the hematopoietic grafts intended for transplantation shortly after collection (some cases of autologous and intra-familiar cord blood transplantation) or for long-distance transport. Also, it would facilitate organization and improve results of autologous or allogenic transplantation procedures.

\section{Acknowledgments}

We are thankful to Mrs. Elisabeth Doutreloux-Volkmann (EFS Nouvelle Aquitaine, Bordeaux) and Miss Nyere Gibson for the language corrections. This study was supported by Etablissement Français du Sang Nouvelle Aquitaine Bordeaux, regional R\&D budget.

Conflict of interest: The authors declared that they have no conflicts of interest.

\section{References}

[1] P.W. Hochachka, Defense strategies against hypoxia and hypothermia, Science 231(4735) (1986) 234-41.

[2] R.G. Boutilier, Mechanisms of cell survival in hypoxia and hypothermia, J Exp Biol 204(Pt 18) (2001) 3171-81.

[3] P.J. Quinn, A lipid-phase separation model of low-temperature damage to biological membranes, Cryobiology 22(2) (1985) 128-46.

[4] U. Rauen, H. de Groot, New insights into the cellular and molecular mechanisms of cold storage injury, J Investig Med 52(5) (2004) 299-309.

[5] U. Rauen, F. Petrat, T. Li, H. De Groot, Hypothermia injury/cold-induced apoptosis--evidence of an increase in chelatable iron causing oxidative injury in spite of low $\mathrm{O} 2-/ \mathrm{H} 2 \mathrm{O} 2$ formation, FASEB journal : official publication of the Federation of American Societies for Experimental Biology 14(13) (2000) 1953-64.

[6] U. Rauen, H. de Groot, Mammalian cell injury induced by hypothermia- the emerging role for reactive oxygen species, Biol Chem 383(3-4) (2002) 477-88.

[7] G. Pless, I.M. Sauer, U. Rauen, Improvement of the cold storage of isolated human hepatocytes, Cell Transplant 21(1) (2012) 23-37.

[8] M.J. Watts, D.C. Linch, Optimisation and quality control of cell processing for autologous stem cell transplantation, Br J Haematol 175(5) (2016) 771-783.

[9] M. Vlaski, L. Negroni, M. Kovacevic-Filipovic, C. Guibert, P. Brunet de la Grange, R. Rossignol, J. Chevaleyre, P. Duchez, X. Lafarge, V. Praloran, J.M. Schmitter, Z. Ivanovic, Hypoxia/hypercapniainduced adaptation maintains functional capacity of cord blood stem and progenitor cells at 4 degrees C, J Cell Physiol 229(12) (2014) 2153-65. 
[10] J. Chevaleyre, L. Rodriguez, P. Duchez, M. Plainfosse, B. Dazey, V. Lapostolle, M. Vlaski, P. Brunet de la Grange, B. Delorme, Z. Ivanovic, A novel procedure to improve functional preservation of hematopoietic stem and progenitor cells in cord blood stored at +4 degrees $\mathrm{c}$ before cryopreservation, Stem Cells Dev 23(15) (2014) 1820-30.

[11] U. Repnik, M.H. Cesen, B. Turk, The Use of Lysosomotropic Dyes to Exclude Lysosomal Membrane Permeabilization, Cold Spring Harb Protoc 2016(5) (2016) pdb prot087106.

[12] J.M. Gutteridge, Y.Y. Hou, Iron complexes and their reactivity in the bleomycin assay for radicalpromoting loosely-bound iron, Free Radic Res Commun 2(3) (1986) 143-51.

[13] M.A. Zieger, M.P. Gupta, Hypothermic preconditioning of endothelial cells attenuates coldinduced injury by a ferritin-dependent process, Free Radic Biol Med 46(5) (2009) 680-91.

[14] P.G. Arthur, X. Niu, P. Rigby, J.H. Steer, G.P. Jeffrey, Oxidative stress causes a decline in lysosomal integrity during hypothermic incubation of rat hepatocytes, Free Radic Biol Med 44(1) (2008) 24-33.

[15] Z. Ivanovic, Hematopoietic stem cells in research and clinical applications: The "CD34 issue", World J Stem Cells 2(2) (2010) 18-23.

[16] T. Kurz, A. Terman, B. Gustafsson, U.T. Brunk, Lysosomes in iron metabolism, ageing and apoptosis, Histochem Cell Biol 129(4) (2008) 389-406.

[17] B. Garner, W. Li, K. Roberg, U.T. Brunk, On the cytoprotective role of ferritin in macrophages and its ability to enhance lysosomal stability, Free Radic Res 27(5) (1997) 487-500.

[18] T. Kurz, A. Leake, T. Von Zglinicki, U.T. Brunk, Relocalized redox-active lysosomal iron is an important mediator of oxidative-stress-induced DNA damage, Biochem J 378(Pt 3) (2004) 1039-45.

[19] G.S. Pavlock, J.H. Southard, J.R. Starling, F.O. Belzer, Lysosomal enzyme release in hypothermically perfused dog kidneys, Cryobiology 21(5) (1984) 521-8.

[20] X. Niu, P.G. Arthur, G.P. Jeffrey, Iron and oxidative stress in cold-initiated necrotic death of rat hepatocyte, Transplant Proc 42(5) (2010) 1563-8.

[21] U. Rauen, U. Kerkweg, D. Weisheit, F. Petrat, R. Sustmann, H. de Groot, Cold-induced apoptosis of hepatocytes: mitochondrial permeability transition triggered by nonmitochondrial chelatable iron, Free Radic Biol Med 35(12) (2003) 1664-78.

[22] H.L. Persson, Z. Yu, O. Tirosh, J.W. Eaton, U.T. Brunk, Prevention of oxidant-induced cell death by lysosomotropic iron chelators, Free Radic Biol Med 34(10) (2003) 1295-305.

[23] M. Tenopoulou, P.T. Doulias, A. Barbouti, U. Brunk, D. Galaris, Role of compartmentalized redoxactive iron in hydrogen peroxide-induced DNA damage and apoptosis, Biochem J 387(Pt 3) (2005)

703-10.

[24] E.L. Punnonen, K. Ryhanen, V.S. Marjomaki, At reduced temperature, endocytic membrane traffic is blocked in multivesicular carrier endosomes in rat cardiac myocytes, Eur J Cell Biol 75(4) (1998) 344-52.

[25] Z. Ivanovic, Hemopoietic stem cell proliferation in Belgrade rats: to complete the parable, Hematol Cell Ther 39(6) (1997) 307-16.

[26] M.D. Fleming, M.A. Romano, M.A. Su, L.M. Garrick, M.D. Garrick, N.C. Andrews, Nramp2 is mutated in the anemic Belgrade (b) rat: evidence of a role for Nramp2 in endosomal iron transport, Proc Natl Acad Sci U S A 95(3) (1998) 1148-53.

[27] Z. Ivanovic, P. Milenkovic, M. Vasiljevska, M. Dekic, Hematopoietic stem cells in the hereditarily anemic Belgrade laboratory (b/b) rat, Exp Hematol 23(11) (1995) 1218-23. 


\section{Figure legends}

Figure 1. Chelatable iron-dependant conservation in hematopoetic progenitors in hypothermia. A) Bleomycin-detectable labile iron pool is estimated in CD34+ cells at D-0 and D-7 of incubation at $4^{\circ} \mathrm{C}$ in air or HH gas mixture. The bars are presented as a mean \pm SD of 8 independent experiments. B) Conservation of $\mathrm{CD}_{3} 4^{+}$cells presented as the average fold change in the number of viable cells (Annexin $\mathrm{V}^{-} / \mathrm{PI}^{-}$) detected in the presence of DFX relative to the number of cells detected in the same experiment without DFX. C) Conservation of the erythroid, granulocyte-monocyte and totals committed progenitors in the presence of the growing concentrations of DFX in air or HH gas mixture. The bars are presented as a mean number of the progenitors relative to D0 level \pm SD of 6 independent experiments. The asterisks indicate a significant difference at $p<0.01\left({ }^{* *}\right)\left({ }^{*}\right)$, WilcoxonMann-Whitney.

Figure 2. Ferritin content and lysosome integrity in $\mathrm{CD} 4^{+}$cells during hypothermia. A) Level of ferritin is determined in $\mathrm{CD} 34^{+}$cells at D-0 and D-7 of incubation at $4^{\circ} \mathrm{C}$ in air or $\mathrm{HH}$ gas mixture. B) Stability of lysosomes is evaluated by acridine orange (AO) using flow cytometry in CD34 ${ }^{+}$cells at D-0 and $\mathrm{D}-7$ of incubation at $4^{\circ} \mathrm{C}$ in air or $\mathrm{HH}$ gas mixture presented in the histogram. One representative of five independent experiments is shown. AO mean fluorescence intensity (MFI) is presented as the mean \pm SD. The asterisks indicate a significant difference at $p<0.01(* *) v s$ D-0 condition, WilcoxonMann-Whitney test.

Figure 3. Conservation of $\mathrm{CD}^{4} 4^{+}$in hypothermia pre-treated with imidazole. A) AO staining of lysosomes in $\mathrm{CD}_{3} 4^{+}$cells at D-0 and D-7 of incubation at $4^{\circ} \mathrm{C}$ in air or $\mathrm{HH}$ gas mixture. B) The bleomycin-detectable labile iron pool is estimated in $\mathrm{CD}_{3} 4^{+}$cells at D-0 and D-7 of incubation at $4^{\circ} \mathrm{C}$ in air or $\mathrm{HH}$ gas mixture. C) $\mathrm{CD} 34^{+}$cell survival after 7 days of incubation at $4^{\circ} \mathrm{C}$ in air or $\mathrm{HH}$ gas mixture. Cell survival is presented as the \% of viable cells (Annexin $\mathrm{V}^{-} / \mathrm{PI}^{-}$). The bars are presented as a mean \pm SD of 5 independent experiments. The asterisks indicate a significant difference at $p<0.01$ $(* *)$ and $p<0.05(*)$, Wilcoxon-Mann-Whitney test. MFI, Mean fluorescence intensity. IMI, imidazole. 
Figure 1

A)

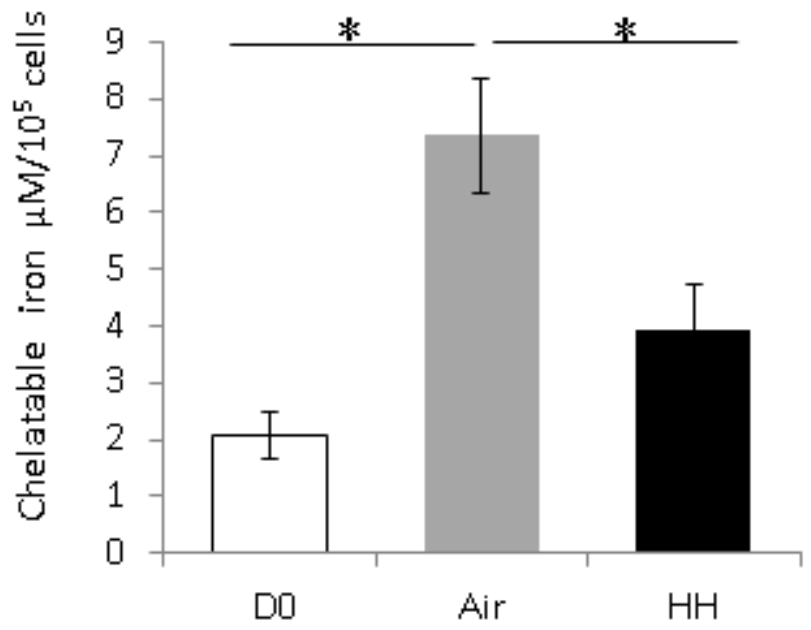

B)

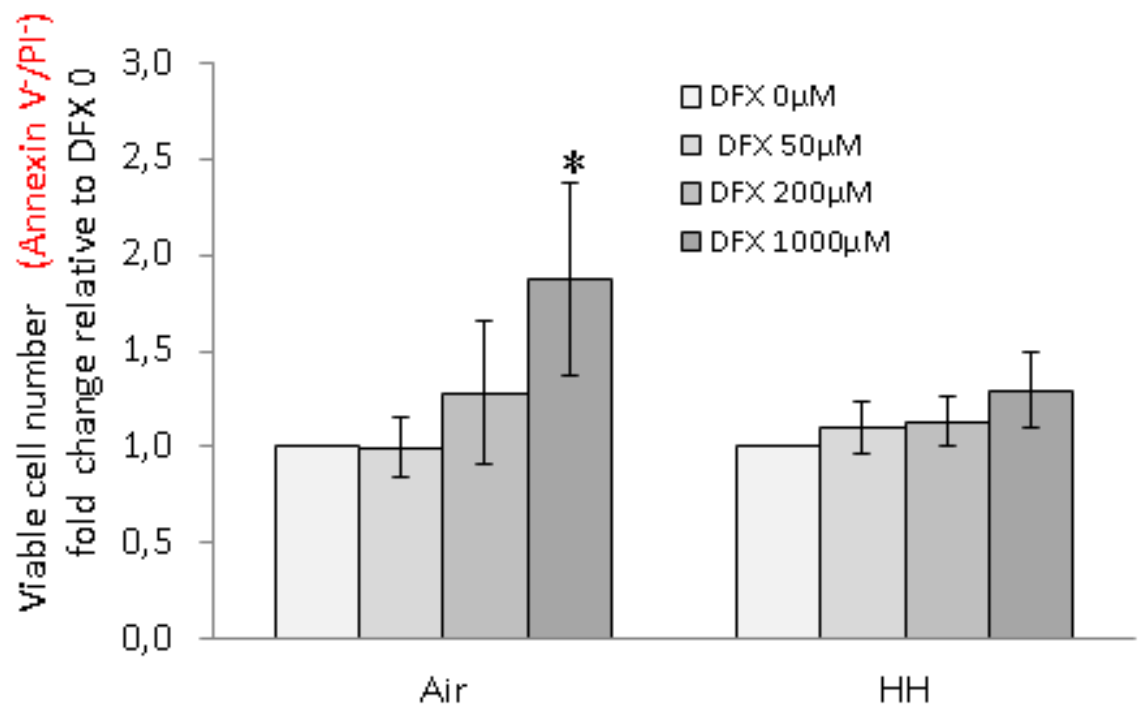

C) BFU-E number relative to DO CFU-GM number relative to DO CFC number relative to DO
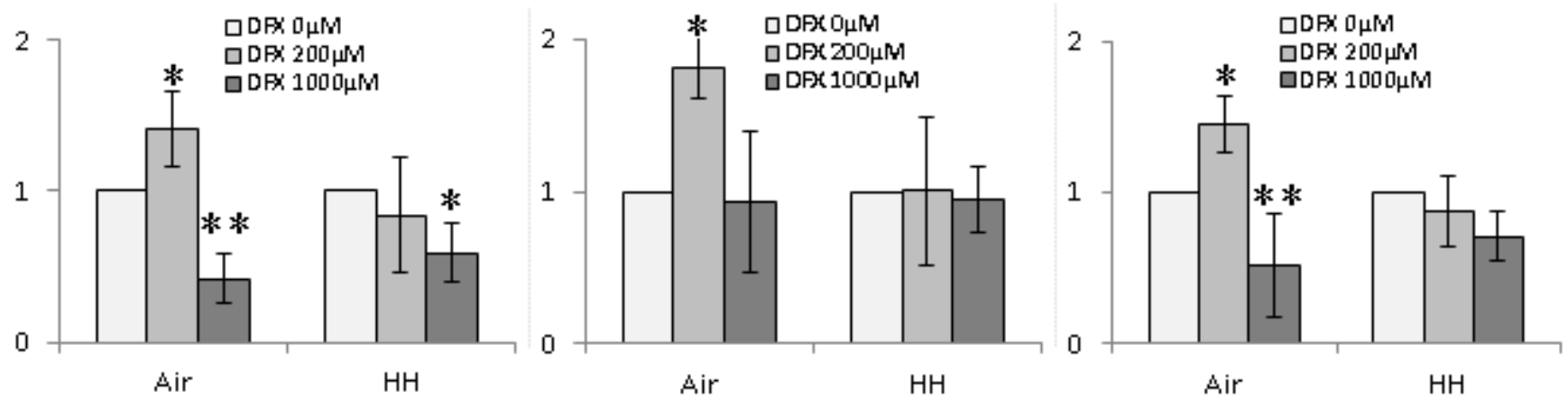


\section{Figure 2}
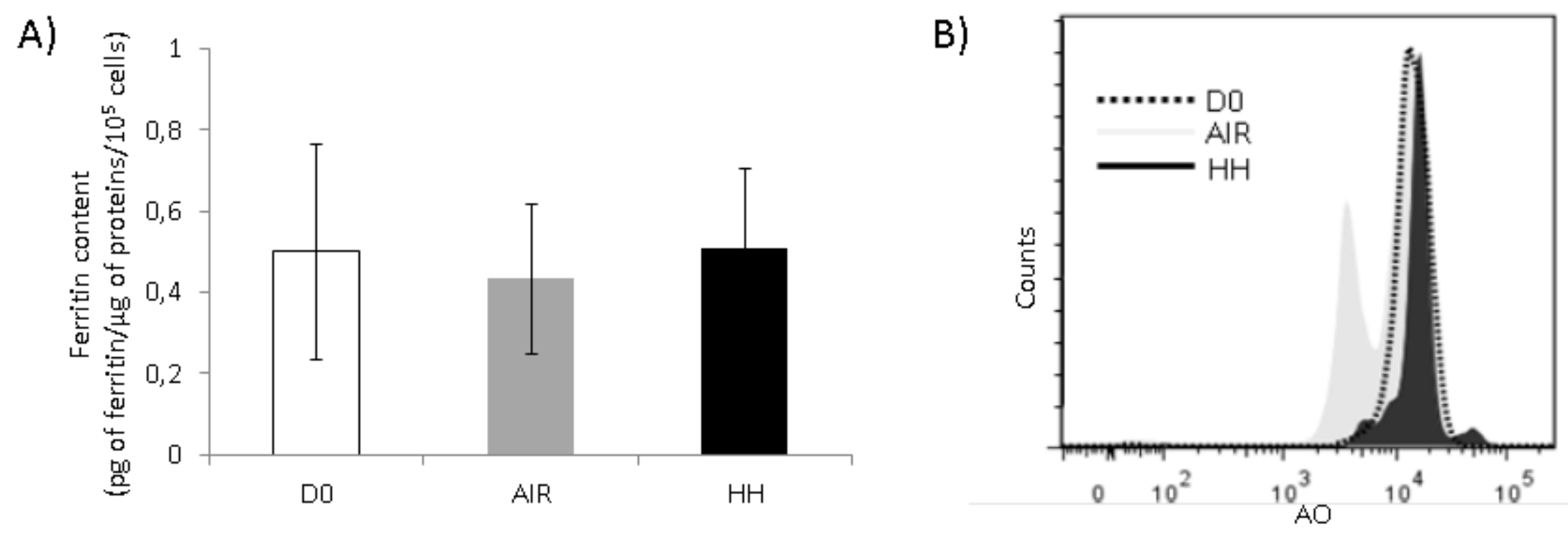

\begin{tabular}{|c|c|c|c|}
\hline Condition & DO & AIR & $\mathrm{HH}$ \\
\hline $\mathrm{MFI}$ & 13310 & $10015 * *$ & 13830 \\
\hline $\mathrm{AO}$ & \pm 1800 & \pm 1480 & \pm 1324 \\
\hline
\end{tabular}


Figure 3

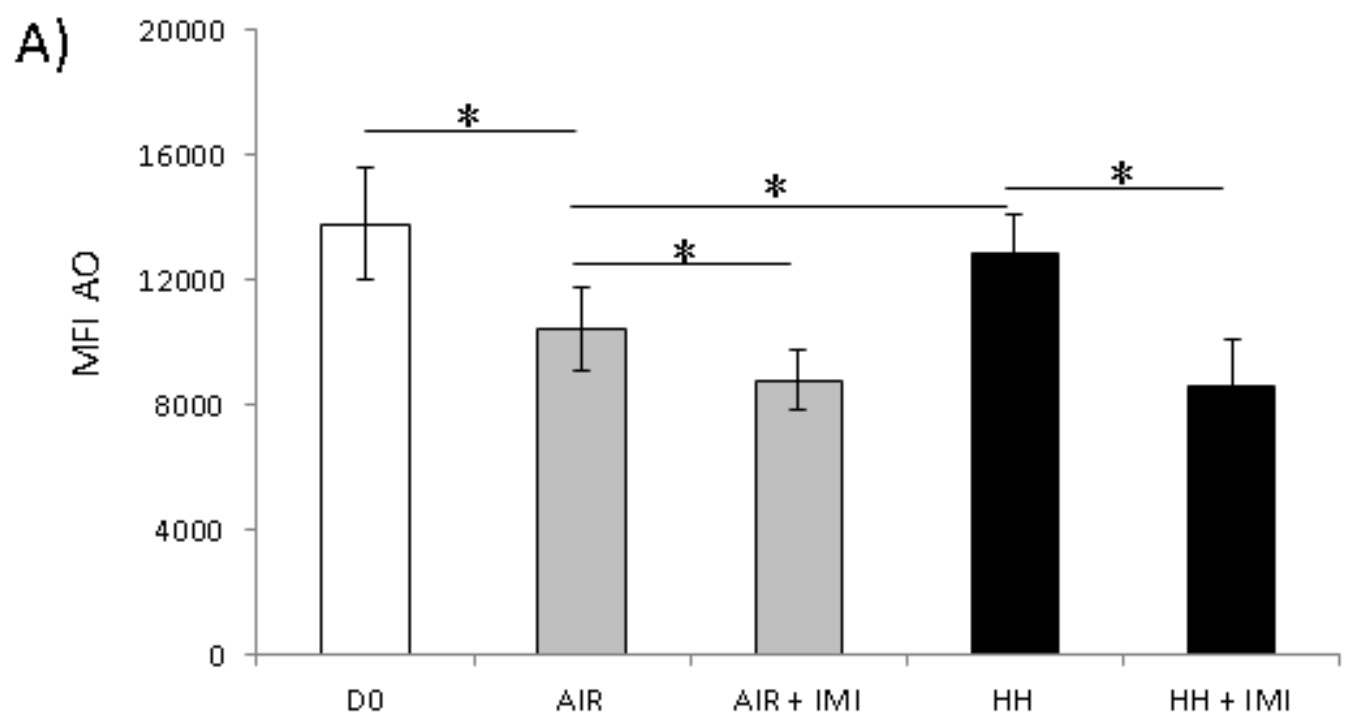

B)

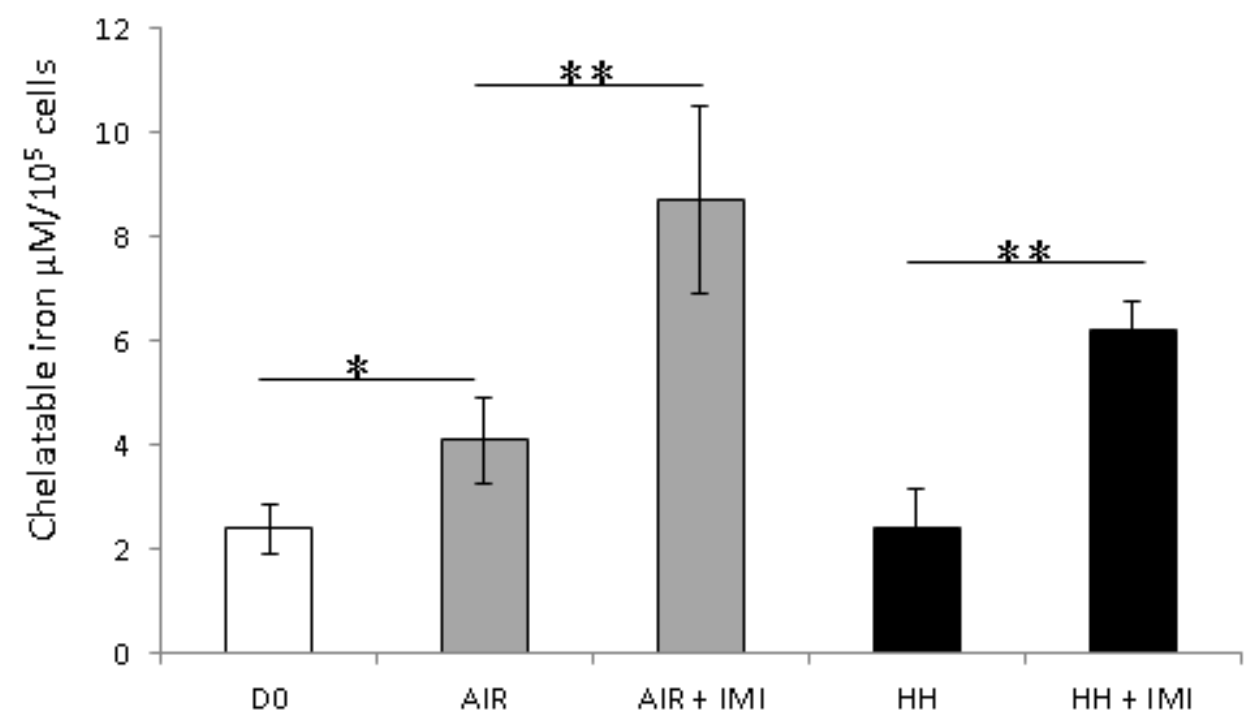

C)

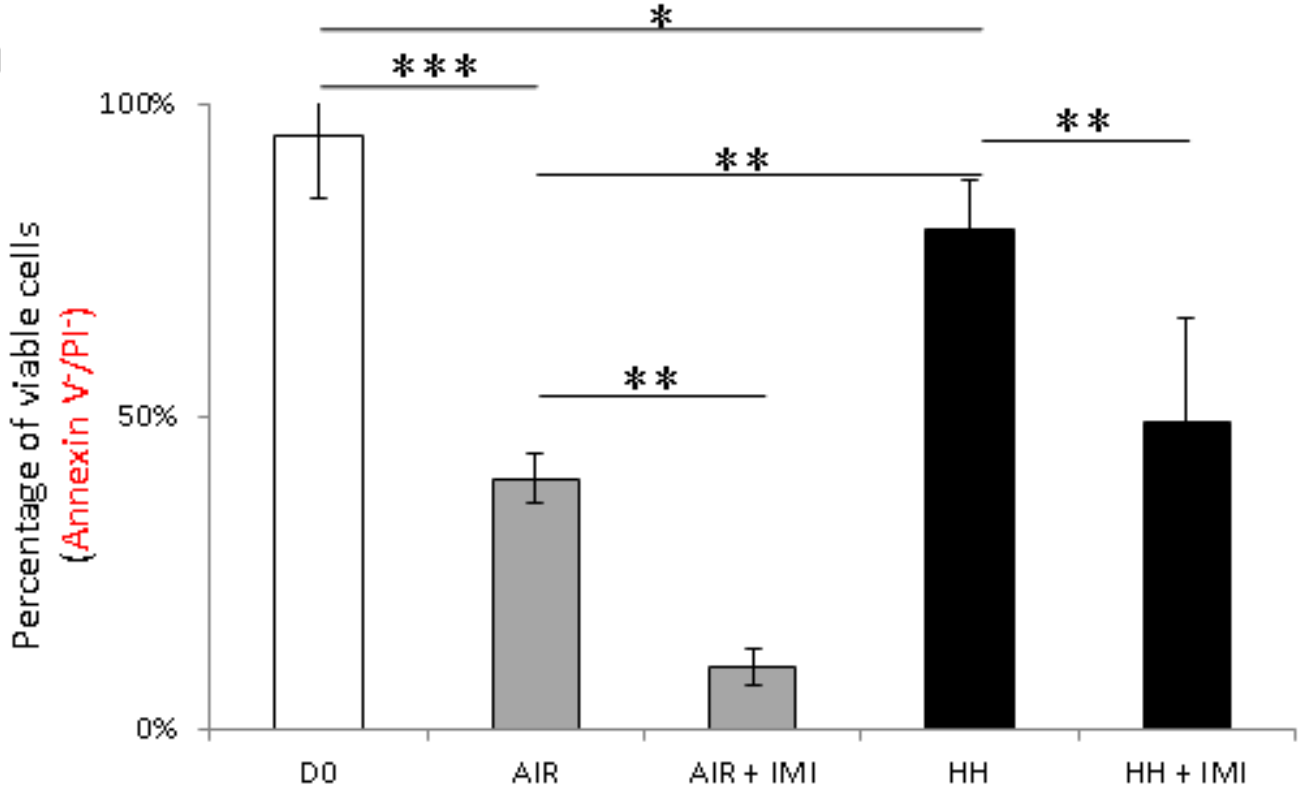

